\title{
Biomechanical Effect of Plate-to-Disc Distance on Surgical and Adjacent Segment in C5/C6 Anterior Cervical Discectomy and Fusion - A Finite Element Analysis
}

\author{
Yuan Xue ( $\nabla$ xueyuanzyy@163.com )

\section{Xing Guo} \\ Tianjin Medical University General Hospital \\ Jiaming Zhou \\ Tianjin Medical University General Hospital

\section{Yueyang Tian} \\ Tianjin Medical University General Hospital

\section{Liang Kang} \\ Tianjin Medical University General Hospital
}

Tianjin Medical University General Hospital https://orcid.org/0000-0002-3371-7994

\section{Research article}

Keywords: Finite element analysis, Plate-to-disc distance, Biomechanical effect, Adjacent-segment degeneration, Spinal fusion, Degenerative disc disease, Cervical vertebrae, spine surgery, Complication

Posted Date: September 25th, 2020

DOI: https://doi.org/10.21203/rs.3.rs-78742/v1

License: @ (i) This work is licensed under a Creative Commons Attribution 4.0 International License. Read Full License

Version of Record: A version of this preprint was published at BMC Musculoskeletal Disorders on April 9th, 2021. See the published version at https://doi.org/10.1186/s12891-021-04218-4. 


\section{Abstract}

Background: The PDD is an important factor affecting the degeneration of adjacent segments after ACDF. However, the most suitable PDD is controversial. This study examined the adjacent intervertebral disc stress, bone graft stress, titanium plate stress and screw stress to evaluate the biomechanical effect of different Plate-to-Disc Distance (PDD) on surgical segment and adjacent segment following C5/C6 anterior cervical discectomy and fusion (ACDF).

Methods: We constructed 10 preoperative finite element models (FEM) of intact C4-C7 segments and validated them in the present study. We simulated ACDF surgery based on the 10 intact models in software. We designed three different distance of Plate-to-Disc titanium plates: L, long PDD (10 mm); S, short PDD $(0 \mathrm{~mm})$; and N, PDD $(5 \mathrm{~mm})$. The changes in C4/C5 and C6/C7 intervertebral disc stress, bone graft stress, titanium plate stress and screw stress were analyzed.

Results: The von Mises stress of C4/C5 and C6/C7 intervertebral discs have no significant differences $(P>0.05)$ in three different PDD groups. Titanium plate stress increased as the PDD decreased. The bone graft stress and screws stress decreased as the PDD decreased. The maximum stress of each part occurred was mostly in the conditions of rotation and lateral bending.

Conclusions: The PDD has no effect on adjacent intervertebral disc stress, but it is an important factor that affecting the bone graft stress, titanium plate stress and screws stress after ACDF. Shorter PDD plate can provide better stability to reduce stress on screws and bone graft, that may be helpful to prevent cage subsidence, pseudarthrosis and instrument failure. This can serve as a reference for clinical choice of plate.

\section{Background}

Anterior cervical discectomy and fusion (ACDF) with plate has been the most popular surgical approach for treating symptomatic cervical disc herniation. Previous studies have reported that patients can achieve significant neurologic recovery and improvement in quality of life after $\mathrm{ACDF}^{1-5}$. However, it has been reported that the cervical arthrodesis with plate can change the biomechanical environment of cervical spine, eventually result in adjacent segment degeneration (ASD) ${ }^{6-8}$.

ASD is defined as the degeneration of adjacent level of spine arthrodesis. Previous studies have been reported that the repeat surgery rate of ACDF patients was $17.4 \%$ due to symptomatic $A S D^{9}$, which seriously affected the patient's satisfaction with the surgery and increased the economic burden on society. There have been studies that suggested plate-to-disc distance (PDD) ${ }^{6}$, graft type $^{10}$, and post-operative cervical alignment ${ }^{11}$ are factors that affect the incidence of ASD. Among them, PDD is considered to be an important factor affecting the development of ASD. However, the biomechanical effect of different PDD on adjacent and surgical segments has not been reported.

Finite element analysis (FEA) has the ability to simulate a variety of complex body structures in a computer and calculate the pressure and stress of each component without any invasion ${ }^{12,13}$. FEA also provide time- and cost- effective means to address various what if scenarios, thereby reducing the need for costly experimental animal and cadaveric studies. Hence, the objective of the present study is to analyze the biomechanical effect of different PDD on adjacent intervertebral disc stress, bone graft stress, titanium plate stress and screw stress precisely using quantitative FEA.

\section{Material/methods}

\section{Construction of the C4-C7 finite element models}

We built 10 nonlinear three-dimensional finite element (FE) models based on computed tomography (CT) scans with interval $0.625 \mathrm{~mm}$ of the cervical spine of 10 healthy volunteers without cervical degeneration. MIMICS 21.0 (Materialise, Leuven, Belgium) software was used to construct the primary geometric structures of the C4-C7 cervical vertebraes based on the CT images. Then, the primary geometries were imported into Geomagic Studio 14.0 (Geomagic, Research Triangle Park, North Carolina, USA) to generate smooth surface models. The 10 models were processed using Solidworks 2019 (Solidworks, Massachusetts, USA) and imported into Hypermesh 14.0 (Altair, Troy, MI, USA) to construct structures such as intervertebral discs, annulus fibrosus, annulus fibers, nucleus pulposus, endplates, ligaments and so on, and mesh. At this point, the three-dimensional finite element models have 
been created. Finally, the boundary conditions and loading conditions of the prepared models were set using ABAQUS 6.9.1 (Dassault Systems Corporation).

The bony structures of the vertebral body include cortical bone, cancellous bone and posterior structure. The cancellous bone region of the vertebrae was set as solid element. The thick of the cortical bone was $1.5 \mathrm{~mm}$. We created the nucleus pulposus and annulus fibrosus with a volume ratio of 4:6 $6^{14}$. Annulus fibers surrounded the ground substance with an inclination to the transverse plane between $15^{\circ}$ and $45^{\circ}$, accounting for approximately $19 \%$ of the entire annulus fibrosus volume ${ }^{14}$. A bond connection was defined between the intervertebral disc and endplates. The cartilages were inserted into the spaces of the bony articular process joints. All cartilages of the articular processes were subjected to a face-to-face frictionless contact with each other ${ }^{14,15}$. Five groups of ligaments, including the anterior longitudinal ligament (ALL), posterior longitudinal ligament (PLL), ligamentum flavum, interspinous ligament and capsular ligament were established using tension-only spring elements and attached to the corresponding vertebrae.

The preoperative C4-C7 FE models and structural details were shown in Fig. 1. The information of ten volunteers was shown in Table 1. The material properties of the FE models are listed in Table 2 and Table $3^{16,17 .}$

\section{Validation of the model}

The range of motion (ROM) of the C4-C7 FE models were predicted with a pure bending moment of $1 \mathrm{~N} m$ for flexion, extension, axial rotation, and lateral bending with $73.6 \mathrm{~N}$ of axial compression superior to $\mathrm{C} 4$, and compared to previous experimental results as shown in Fig. 2. The predicted ROM from the established models showed good agreement with published experimental results $^{18}$.

\section{Surgery simulation}

During the actual surgery, the $\mathrm{C5} / \mathrm{C} 6$ anterior longitudinal ligament, $\mathrm{C} 5 / \mathrm{C} 6$ disc, inferior endplate of $\mathrm{C} 5$, superior endplate of $\mathrm{C} 6$ and $\mathrm{C} 5 / \mathrm{C} 6$ posterior longitudinal ligament were resected. We deleted the corresponding structures to simulate the surgery more precisely. In the present study, three different PDD plates: $0 \mathrm{~mm}, 5 \mathrm{~mm}, 10 \mathrm{~mm}$ plates and self-tapping screws were simulated. The screws were fixed in parallel to the endplates in all postoperative models. The 10 postoperative models was loaded in flexion, extension, axial rotation, and lateral bending by imposing a pure moment of $1.0 \mathrm{~N} \cdot \mathrm{m}$ on $\mathrm{C} 4$ with $73.6 \mathrm{~N}$ of axial precompression superior to the upper endplate of $\mathrm{C} 4$. The lower endplate of $\mathrm{C} 7$ was firmly fixed in all degrees of freedom. The postoperative $\mathrm{C} 4-\mathrm{C} 7$ FE models with different PDD plates were shown in Fig. 3. We choose the Mises stress of adjacent intervertebral disc, the titanium plate, bone graft and screws as the parameters to evaluate mechanical effect of three different PDD plates.

\section{Statistical Analysis}

Differences between groups were calculated by one-way analysis of variance (ANOVA) or chi-squared test in SPSS Version 25.0, (SPSS Inc., Chicago, IL). A P value of less than 0.05 was considered significant. Results are presented as mean \pm standard deviation.

\section{Results}

The Mises stress of adjacent intervertebral disc, bone graft, titanium plate and screw under different load in different PDD titanium plate groups are shown in Table 3

\section{The Mises stress of adjacent intervertebral disc}

The Mises stress distribution diagram of adjacent intervertebral discs with different PDD titanium plates in different loading conditions are shown in Fig. 4. For the upper adjacent segment (C4/C5), no significant differences were found in the Mises stress of adjacent intervertebral disc among the three different PDD groups in flexion, extension, axial rotation, and lateral bending loading

Page $3 / 13$ 
conditions. $(P>0.05)$. Additionally, for the lower adjacent segment $(C 6 / C 7)$, there was also no statistical difference among the three groups in different loading conditions. $(P>0.05)$.

\section{The Mises stress of bone graft}

The Mises stress distribution diagram of bone graft with different PDD titanium plates in different loading conditions are shown in Fig. 5. The Mises stress of bone graft in the three groups were statistically different $(P<0.05)$. The bone graft stress decreased as the PDD decreased in all different loading conditions.

\section{The Mises stress of titanium plate}

The Mises stress distribution diagram of titanium plate with different PDD titanium plates in different loading conditions are shown in Fig. 6. A significant difference was found in the Mises stress of titanium plates among the three different PDD groups $(P<0.05)$. The stress of titanium plate increased as the PDD decreased in all different loading conditions.

\section{The Mises stress of screw}

The Mises stress distribution diagram of screws with different PDD titanium plates in different loading conditions are shown in Fig. 6. A significant difference in the Mises stress of screws was found in the three different PDD groups $(P<0.05)$. The screw stress decreased as the PDD decreased in all different loading conditions.

\section{Discussion}

Anterior cervical discectomy and fusion has been an effective procedure for treating symptomatic cervical spondylotic myelopathy since it was initially described by Robinson and Smith ${ }^{19}$. It has produced good results in the treatment of many degenerative cervical lesions ${ }^{20-22}$. With the development of surgical instruments and surgical techniques, titanium plate has been routinely used in ACDF surgery. Reasonable use of titanium plate can provide immediate stability in early postoperative period, which can prevent bone graft subsidence, bone graft extrusion and improve fusion rates, and reduce the need for external immobilization ${ }^{22-24}$. However, it has been reported that the use of short PDD plate will accelerate the degeneration of adjacent segments, eventually result in symptomatic $\mathrm{ASD}^{25}$.

ASD as a complication of ACDF has been reported to cause $17.4 \%$ of ACDF patients to have to undergo a second surgery ${ }^{9}$, which has seriously affected patient's quality of life and increased the economic burden on families and society.

Various scholars have different opinions regarding PDD in ACDF. Chung et al. ${ }^{6}$ reported that 177 patients who underwent anterior cervical discectomy and fusion using cervical plates, with follow-up periods of at least 10 years. They found most clinical adjacentsegment degeneration appeared on the patients with a PDD less than $5 \mathrm{~mm}$. So they considered that to prevent adjacent segment degeneration, the PDD should be $5 \mathrm{~mm}$ or more if possible. In addition, Yu et al. ${ }^{25}$ agreed that PDD $<5 \mathrm{~mm}$ is a risk factor for ASD by the logistic regression analysis based on 138 patients. However, Yang et al. ${ }^{26}$ retrospectively reviewed 218 patients who underwent anterior cervical arthrodesis with plating and considered that there is no correlation between PDD and the incidence of ASD, but PDD > $5 \mathrm{~mm}$ could avoid the development of adjacent segment ossification. In a cadaver study, Raj D found that there was no statistical difference at intervertebral disc and intervertebral motion of adjacent segments with plate or not. Therefore, it remains controversial whether different PDD plate will affect the incidence of ASD.

FEA have been widely used for a biomechanical analysis of the cervical spine because they can analyze various results quantitatively without any invasion. In the present study, we constructed 10 three-dimensional finite element C4-C7 models based on cervical CT images of 10 volunteers. Considering that cervical disc lesions mostly occur in the $\mathrm{C} 5 / \mathrm{C} 6$ segments, we selected the C5/C6 segment as the surgical segment so that the results could be suitable for more patients. 
In our study, no significant differences were found in the adjacent intervertebral disc stress in the three different PDD groups. This result indicates that PDD does not affect the adjacent intervertebral disc stress. It has been reported that excessive loading can induce degeneration of intervertebral discs. So, we can conclude that the titanium plates of different PDD will not promote the degeneration of adjacent segments by increasing the intervertebral disc stress of adjacent segments. This can further validate the clinical findings of Yang et al. ${ }^{26}$ that there is no correlation between PDD and the incidence of ASD.

As for the bone graft stress, we found that the bone graft stress decreased as the PDD decreased. This may be related to the fact that the short PDD plate increases the stiffness of the surgical segment and provides better stability. Although the most appropriate stress on bone graft is not clearly, excessive stress on the bone graft may result in fusion failure because of graft dislodgement and endplate fracture ${ }^{27}$. Furthermore, non-fusion is an important reason for the failure of instruments ${ }^{28}$. Considering bone graft stress and fusion rate, shorter PDD plate is safer because that shorter PDD is helpful to prevent bone graft subsidence and instrument failure from a biomechanical point of view.

The stress of titanium plate increased as the PDD decreased, which shows that as the length of the plate increases, the stress increases accordingly. This is due to the longer torque of the long plate. Of course, this result also explains that long titanium plates can carry more stress, which provides better stability. Although the increase of stress of the plate may cause the plate to break, the increase of the plate stress among different PDD groups is not obvious in the average value.

The screw stress decreased as the PDD decreased. As the length of the steel plate increases, the screw stress decreases. This may be caused by that the most of the overall stress is mostly carried by the plate. Screw loosening and breakage are associated with metal fatigue via pseudarthrosis, which were most dangerous complications in cervical anterior plating fixation. So shorter PDD plate plays an important role in preventing screws breakage and loosening. Yang et al. ${ }^{26}$ found when the end point of plate violates the adjacent space, the incidence of ASD is the lowest among different PDD groups. They considered that this may be because the formation of ossification improves the stability of adjacent segments. However, they do not advocate the use of plates that can invade adjacent space. Considering that the strength of the screw is weaker than that of the plate ${ }^{28}$, we believe that choosing a slightly shorter PDD plate is more conducive to postoperative recovery. Of course, we also don't recommend that the PDD is too small to violate the adjacent space.

In addition, we find that the maximum stress of each part occurred was mostly in the conditions of rotation and lateral bending, so we recommend that patients should avoid excessive rotation and lateral bending during early postoperative period to prevent screws breakage, fusion failure, endplate fracture and other complications.

The present study has a number of limitations: 1) Muscles and other soft tissue were not constructed in the models, however, these structures are extremely important for spine biomechanics research; 2) In addition, the screws were designed as solid cylinders bound to the cage or plate, and the threads on the screws were not modeled; 3) The model was based on only 10 persons, which may limit the present study's applicability to a wider population; 4) Some simplifications were carried out in the prosthesis geometry, for example, we simplify the Cancellous bone as a solid structure which may affect the distribution and geometric deformation of the load. Although completely duplicating the result of in vivo studies in FE analysis was impossible, this study effectively shows the biomechanical differences among different PDD plate groups.

\section{Conclusions}

The PDD has no effect on adjacent intervertebral discs stress, but it is an important factor that affecting the bone graft stress, titanium plate stress and screw stress after ACDF. Shorter PDD does not affect the incidence of ASD through the increase of the adjacent intervertebral discs stress, but it can provide better stability to reduce stress on screws and bone graft which may be helpful to prevent bone graft subsidence, pseudarthrosis and instrument failure. This can serve as a reference for clinical choice of plate.

\section{Abbreviations}

ACDF: anterior cervical discectomy and fusion; ASD: adjacent segment degeneration; PDD: plate-to-disc distance; FEA: finite element analysis; FE: finite element; CT: computed tomography; ROM: the range of motion; ALL: anterior longitudinal ligament; PLL: 
posterior longitudinal ligament: CL: capsular ligament; LF: ligamentum flavum; ISL: interspinous ligament; SL: supraspinous ligaments

\section{Declarations}

\section{Acknowledgements}

We extend sincere gratitude to the staff of the Department of Orthopaedic Surgery for their assistance during this study.

\section{Authors' contributions}

$Y X$ and JMZ participated in the design of this study. XG, YYT, LK, RZ carried out the studies and performed the statistical analysis. $X G, J M Z, Y Y T$, and $Y X$ drafted the manuscript. All authors read and approved the final manuscript.

\section{Funding}

This study was funded by the National Natural Science Foundation of China (Grant No 81871124).

\section{Availability of data and materials}

The datasets generated and/or analysed during the current study are not publicly available due to individual privacy but are available from the corresponding author on reasonable request.

\section{Ethics approval and consent to participate}

This article contains a study with human participants, and the study protocol was approved by the Investigation and Ethics Committee of the Tianjin Medical University General Hospital (reference number IRB2019-WZ-145). Informed consent for this study was obtained from all patients by both written and verbal.

\section{Consent for publication}

Applicable. Written informed consent was obtained from the participants for the publication of this report and any accompanying images.

\section{Competing interests}

The authors declare that they have no competing interests.

\section{References}

1. Aebi M, Zuber K, Marchesi D. Treatment of cervical spine injuries with anterior plating. Indications, techniques, and results. Spine 1991;16:S38-45.

2. Heidecke V, Rainov NG, Burkert W. Anterior cervical fusion with the Orion locking plate system. Spine 1998;23:1796-802; discussion 803.

3. Katsuura A, Hukuda S, Imanaka T, et al. Anterior cervical plate used in degenerative disease can maintain cervical lordosis. Journal of spinal disorders 1996;9:470-6.

4. Tribus CB, Corteen DP, Zdeblick TA. The efficacy of anterior cervical plating in the management of symptomatic pseudoarthrosis of the cervical spine. Spine 1999;24:860-4.

5. Wang JC, McDonough PW, Endow KK, et al. Increased fusion rates with cervical plating for two-level anterior cervical discectomy and fusion. Spine 2000;25:41-5.

6. Chung JY, Kim SK, Jung ST, et al. Clinical adjacent-segment pathology after anterior cervical discectomy and fusion: results after a minimum of 10-year follow-up. The spine journal : official journal of the North American Spine Society 2014;14:2290-8.

7. Matsumoto M, Okada E, Ichihara D, et al. Anterior cervical decompression and fusion accelerates adjacent segment degeneration: comparison with asymptomatic volunteers in a ten-year magnetic resonance imaging follow-up study. Spine 
2010;35:36-43.

8. Wang F, Hou HT, Wang P, et al. Symptomatic adjacent segment disease after single-lever anterior cervical discectomy and fusion: Incidence and risk factors. Medicine 2017;96:e8663.

9. Burkhardt BW, Brielmaier M, Schwerdtfeger K, et al. Smith-Robinson procedure with and without Caspar plating as a treatment for cervical spondylotic myelopathy: A 26-year follow-up of 23 patients. European spine journal : official publication of the European Spine Society, the European Spinal Deformity Society, and the European Section of the Cervical Spine Research Society 2017;26:1246-53.

10. Samartzis $\mathrm{D}$, Shen FH, Goldberg EJ, et al. Is autograft the gold standard in achieving radiographic fusion in one-level anterior cervical discectomy and fusion with rigid anterior plate fixation? Spine 2005;30:1756-61.

11. Katsuura A, Hukuda S, Saruhashi Y, et al. Kyphotic malalignment after anterior cervical fusion is one of the factors promoting the degenerative process in adjacent intervertebral levels. European spine journal : official publication of the European Spine Society, the European Spinal Deformity Society, and the European Section of the Cervical Spine Research Society 2001;10:3204.

12. Nikkhoo M, Hsu YC, Haghpanahi M, et al. A meta-model analysis of a finite element simulation for defining poroelastic properties of intervertebral discs. Proceedings of the Institution of Mechanical Engineers. Part $\mathrm{H}$, Journal of engineering in medicine 2013;227:672-82.

13. Schmidt H, Galbusera F, Rohlmann A, et al. What have we learned from finite element model studies of lumbar intervertebral discs in the past four decades? Journal of biomechanics 2013;46:2342-55.

14. Denoziere G, Ku DN. Biomechanical comparison between fusion of two vertebrae and implantation of an artificial intervertebral disc. Journal of biomechanics 2006;39:766-75.

15. Rong $X$, Wang B, Ding C, et al. The biomechanical impact of facet tropism on the intervertebral disc and facet joints in the cervical spine. The spine journal : official journal of the North American Spine Society 2017;17:1926-31.

16. Yoganandan N, Kumaresan S, Pintar FA. Biomechanics of the cervical spine Part 2. Cervical spine soft tissue responses and biomechanical modeling. Clinical biomechanics 2001;16:1-27.

17. Wheeldon JA, Stemper BD, Yoganandan N, et al. Validation of a finite element model of the young normal lower cervical spine. Annals of biomedical engineering 2008;36:1458-69.

18. Panjabi MM, Crisco JJ, Vasavada A, et al. Mechanical properties of the human cervical spine as shown by three-dimensional load-displacement curves. Spine 2001;26:2692-700.

19. Smith GW, Robinson RA. The treatment of certain cervical-spine disorders by anterior removal of the intervertebral disc and interbody fusion. The Journal of bone and joint surgery. American volume 1958;40-a:607-24.

20. Bohlman HH, Emery SE, Goodfellow DB, et al. Robinson anterior cervical discectomy and arthrodesis for cervical radiculopathy. Long-term follow-up of one hundred and twenty-two patients. The Journal of bone and joint surgery. American volume 1993;75:1298-307.

21. Gore DR, Sepic SB. Anterior cervical fusion for degenerated or protruded discs. A review of one hundred forty-six patients. Spine 1984;9:667-71.

22. Lee $\mathrm{CH}, \mathrm{Hyun} \mathrm{SJ}, \mathrm{Kim} \mathrm{MJ}$, et al. Comparative analysis of 3 different construct systems for single-level anterior cervical discectomy and fusion: stand-alone cage, iliac graft plus plate augmentation, and cage plus plating. Journal of spinal disorders \& techniques 2013;26:112-8.

23. Song KJ, Taghavi CE, Lee KB, et al. The efficacy of plate construct augmentation versus cage alone in anterior cervical fusion. Spine 2009;34:2886-92.

24. Kaiser MG, Haid RW, Jr., Subach BR, et al. Anterior cervical plating enhances arthrodesis after discectomy and fusion with cortical allograft. Neurosurgery 2002;50:229-36; discussion 36-8.

25. Yu C, Mu X, Wei J, et al. In-Depth Analysis on Influencing Factors of Adjacent Segment Degeneration After Cervical Fusion. Medical science monitor : international medical journal of experimental and clinical research 2016;22:4902-10.

26. Yang H, Lu X, He H, et al. Longer plate-to-disc distance prevents adjacent-level ossification development but does not influence adjacent-segment degeneration. Spine 2015;40:E388-93.

Page $7 / 13$ 
27. Ning X, Wen Y, Xiao-Jian Y, et al. Anterior cervical locking plate-related complications; prevention and treatment recommendations. International orthopaedics 2008;32:649-55.

28. Song KJ, Choi BW, Ham DH, et al. Prognosis of hardware-related problems in anterior cervical discectomy and fusion with cage and plate constructs. World neurosurgery 2019.

\section{Tables}

Table 1

The material properties of the spinal soft tissues and hard tissues used in the finite element model.

\begin{tabular}{|llll|}
\hline Description & Element Type & Young's Modulus (MPa) & Poisson's Ratio \\
\hline Cortical bone & C3D4 & 12,000 & 0.3 \\
\hline Cancellous bone & C3D4 & 100 & 0.2 \\
\hline Posterior elements & C3D4 & 3500 & 0.25 \\
\hline Facet cartilage & C3D4 & 10.4 & 0.4 \\
\hline End plate & C3D4 & 600 & 0.3 \\
\hline Nucleus pulposus & C3D4 & 1 & 0.49 \\
\hline Annulus ground substance & C3D4 & 3.4 & 0.4 \\
\hline Annulus fibers & T3D2 & 450 & 0.45 \\
\hline Titanium plate & C3D4 & 120,000 & 0.3 \\
\hline Titanium screw & C3D4 & 120,000 & 0.3 \\
\hline
\end{tabular}

Table 2

The material properties of the ligaments

\begin{tabular}{|c|c|c|c|c|c|c|c|c|c|}
\hline ALL & & PLL & & LF & & ISL & & $\mathrm{CL}$ & \\
\hline $\begin{array}{l}\text { Displacement } \\
(\mathrm{mm})\end{array}$ & $\begin{array}{l}\text { Force } \\
\text { (N) }\end{array}$ & $\begin{array}{l}\text { Displacement } \\
(\mathrm{mm})\end{array}$ & $\begin{array}{l}\text { Force } \\
\text { (N) }\end{array}$ & $\begin{array}{l}\text { Displacement } \\
(\mathrm{mm})\end{array}$ & $\begin{array}{l}\text { Force } \\
(\mathrm{N})\end{array}$ & $\begin{array}{l}\text { Displacement } \\
(\mathrm{mm})\end{array}$ & $\begin{array}{l}\text { Force } \\
\text { (N) }\end{array}$ & $\begin{array}{l}\text { Displacement } \\
(\mathrm{mm})\end{array}$ & $\begin{array}{l}\text { Force } \\
\text { (N) }\end{array}$ \\
\hline 0 & 0 & 0 & 0 & 0 & 0 & 0 & 0 & 0 & 0 \\
\hline 1 & 35.5 & 0.9 & 1.33 & 1.7 & 2.2 & 1.2 & 0.75 & 1.7 & 2.452 \\
\hline 2 & 64.9 & 2 & 29.0 & 3.74 & 45.9 & 2.7 & 16.9 & 3.9 & 53.6 \\
\hline 4 & 89.7 & 3 & 51.4 & 5.61 & 82.9 & 4.0 & 24.4 & 5.8 & 87.9 \\
\hline 5 & 108.6 & 4 & 71.38 & 7.48 & 119.6 & 5.4 & 29.5 & 7.7 & 109.4 \\
\hline \multirow[t]{2}{*}{6} & 119.6 & 5 & 85.8 & 9.35 & 133.7 & 6.7 & 32.9 & 9.7 & 125.8 \\
\hline & & 6 & 94.7 & 11.3 & 147.2 & 8.1 & 34.9 & 11.5 & 134.8 \\
\hline
\end{tabular}


Table 3

The von Mises stress of the structures in different lengths of titanium plates

\begin{tabular}{|c|c|c|c|c|}
\hline von Mises stress (MPa) & & $\mathrm{PDD}=0 \mathrm{~mm}$ & $\mathrm{PDD}=5 \mathrm{~mm}$ & PDD = $10 \mathrm{~mm}$ \\
\hline \multirow[t]{4}{*}{ C4/C5 Intervertebral disc } & Flexion & $1.417 \pm 0.297$ & $1.411 \pm 0.257$ & $1.422 \pm 0.271$ \\
\hline & Extension & $1.337 \pm 0.027$ & $1.333 \pm 0.019$ & $1.346 \pm 0.032$ \\
\hline & Bending & $1.382 \pm 0.038$ & $1.426 \pm 0.119$ & $1.388 \pm 0.041$ \\
\hline & Rotation & $1.384 \pm 0.047$ & $1.378 \pm 0.036$ & $1.387 \pm 0.038$ \\
\hline \multirow[t]{4}{*}{ C6/C7 Intervertebral disc } & Flexion & $1.483 \pm 0.036$ & $1.476 \pm 0.045$ & $1.455 \pm 0.030$ \\
\hline & Extension & $1.425 \pm 0.027$ & $1.419 \pm 0.016$ & $1.413 \pm 0.018$ \\
\hline & Bending & $1.402 \pm 0.030$ & $1.415 \pm 0.032$ & $1.398 \pm 0.020$ \\
\hline & Rotation & $1.351 \pm 0.170$ & $1.292 \pm 0.170$ & $1.224 \pm 0.080$ \\
\hline \multirow[t]{4}{*}{ Bone graft } & Flexion & $0.255 \pm 0.040 \mathrm{~b} \mathrm{c}$ & $0.307 \pm 0.025$ a c & $0.400 \pm 0.031 \mathrm{a} \mathrm{b}$ \\
\hline & Extension & $1.527 \pm 0.051 \mathrm{~b} \mathrm{c}$ & $1.668 \pm 0.042 \mathrm{a} \mathrm{c}$ & $1.812 \pm 0.053 \mathrm{a} \mathrm{b}$ \\
\hline & Bending & $1.522 \pm 0.084$ b c & $1.868 \pm 0.057$ a c & $2.308 \pm 0.055 a b$ \\
\hline & Rotation & $1.620 \pm 0.026$ b c & $1.714 \pm 0.053$ a c & $1.945 \pm 0.140 \mathrm{a} \mathrm{b}$ \\
\hline \multirow[t]{4}{*}{ Titanium plate } & Flexion & $57.886 \pm 3.374$ b c & $48.363 \pm 4.237$ a c & $36.822 \pm 1.049 a b$ \\
\hline & Extension & $58.069 \pm 6.173$ b c & $41.552 \pm 3.822$ a c & $24.791 \pm 1.740 a b$ \\
\hline & Bending & $94.691 \pm 1.859$ b c & $83.956 \pm 2.769$ a c & $73.790 \pm 1.708 a b$ \\
\hline & Rotation & $68.463 \pm 2.529 \mathrm{~b} \mathrm{c}$ & $62.311 \pm 2.526$ a c & $57.824 \pm 0.929 a \mathrm{~b}$ \\
\hline \multirow[t]{4}{*}{ Screw } & Flexion & $32.983 \pm 1.238 \mathrm{~b} \mathrm{c}$ & $42.075 \pm 3.569$ a c & $58.018 \pm 3.083 a b$ \\
\hline & Extension & $34.820 \pm 1.386$ b c & $58.166 \pm 3.206$ a c & $95.603 \pm 22.040 \mathrm{ab}$ \\
\hline & Bending & $55.388 \pm 1.090 \mathrm{~b} \mathrm{c}$ & $60.705 \pm 1.258$ a c & $66.406 \pm 0.647 a b$ \\
\hline & Rotation & $56.617 \pm 1.467$ b c & $64.038 \pm 1.663$ a c & $75.025 \pm 2.727 \mathrm{a} \mathrm{b}$ \\
\hline
\end{tabular}

\section{Figures}
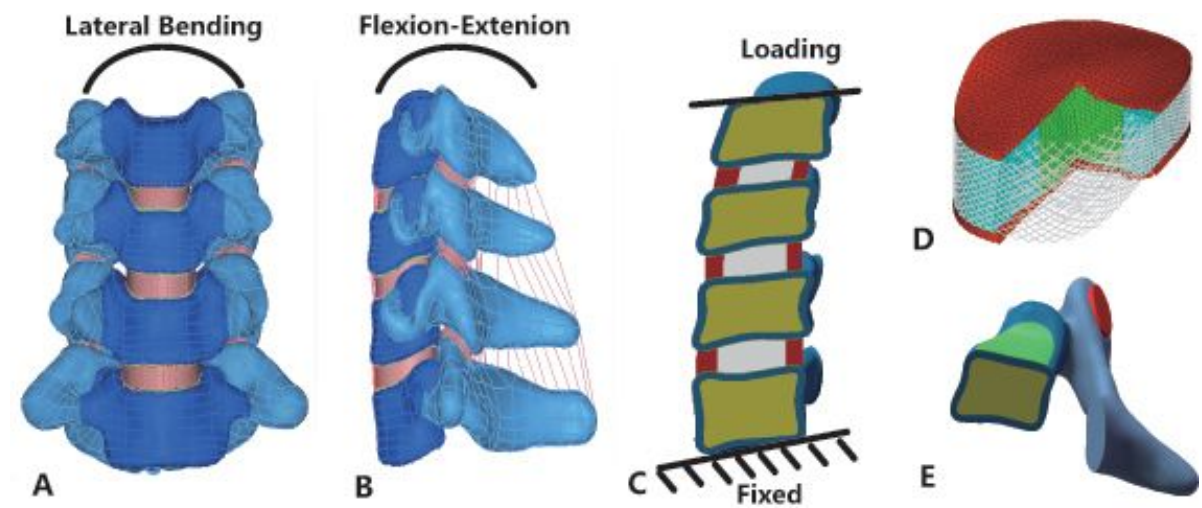

Figure 1 
Finite element models of preoperative and postoperative $\mathrm{C} 4-\mathrm{C} 7$ cervical spine and other structures and details. (A) Frontal view of preoperative model; (B) Lateral view of preoperative model; (C) Loading and boundary condition; (D) Intervertebral disc details; (E) Vertebral body details;
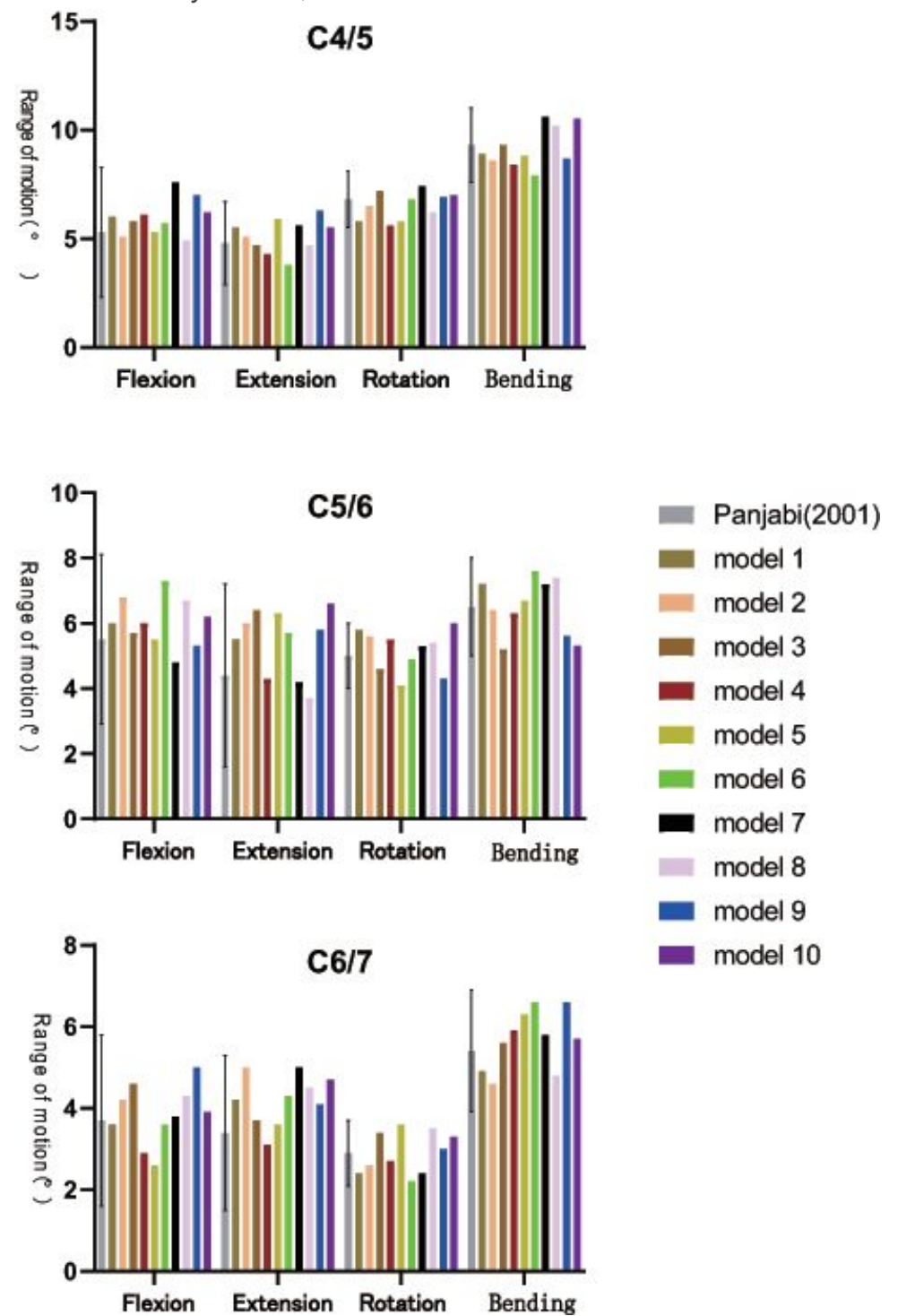

Figure 2

The predicted ranges of motion (ROM) of the preoperative model are validated by previous published study 

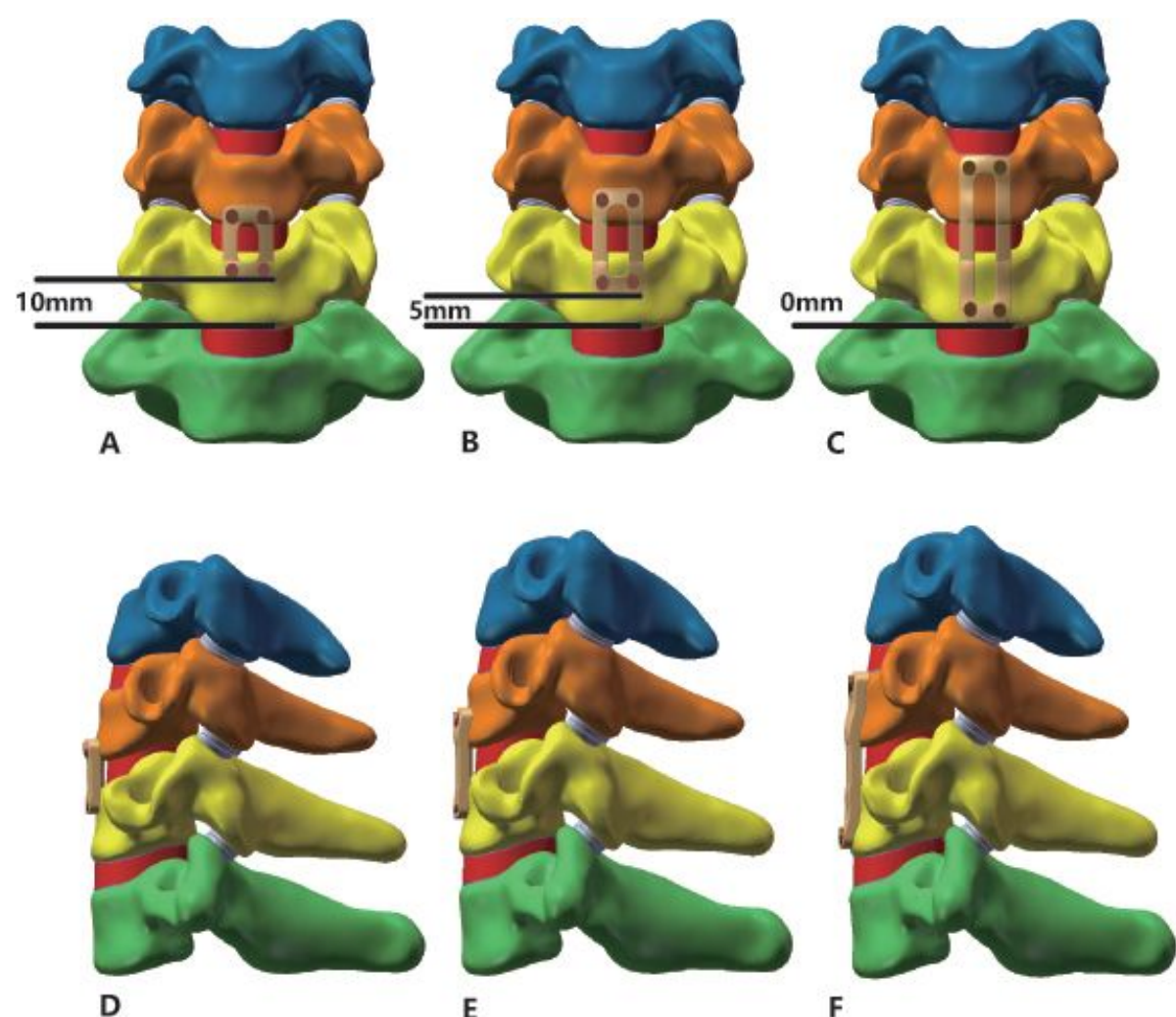

Figure 3

(A and D) Frontal and lateral view of postoperative model with long PDD titanium plate; (B and E) Frontal and lateral view of postoperative model with middle PDD titanium plate; (C and F) Frontal and lateral view of postoperative model with short PDD titanium plate

\section{Image not available with this version}

Figure 4

The Mises stress distribution diagram of adjacent intervertebral discs with different PDD titanium plates in different loading conditions (A: C4/C5; B: C6/C7) 


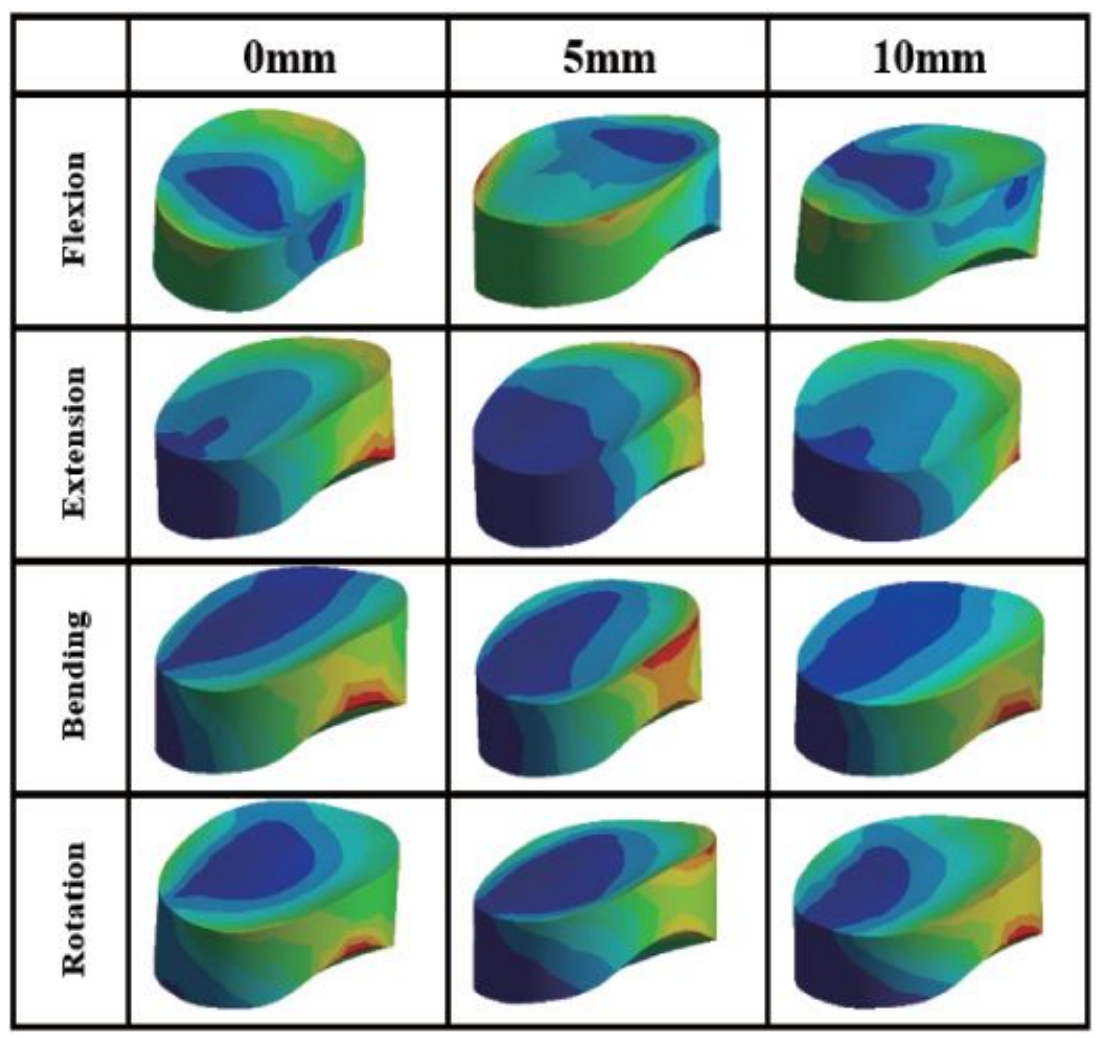

Figure 5

The Mises stress distribution diagram of bone graft with different PDD titanium plates in different loading conditions 


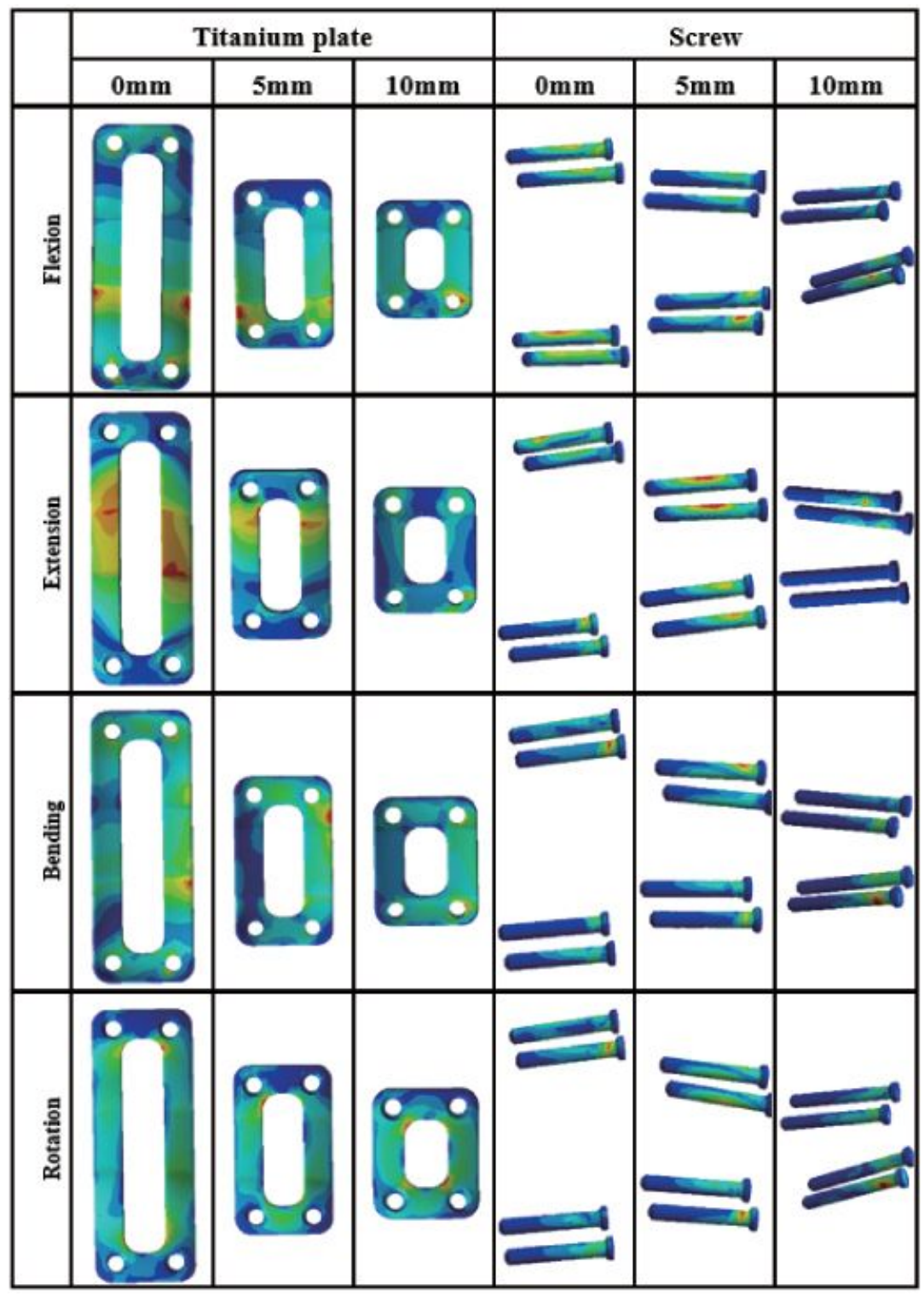

Figure 6

The Mises stress distribution diagram of titanium plate and screw with different PDD titanium plates in different loading conditions 